\title{
Epigraphers and Encoders: Strategies for Teaching and Learning Digital Epigraphy
}

\author{
Gabriel Bodard ${ }^{\star}$ and Simona Stoyanova ${ }^{\dagger}$ \\ *University of London, \\ ${ }^{\dagger}$ University of Leipzig
}

\begin{abstract}
This chapter will discuss the EpiDoc (TEI markup for epigraphy and papyrology) training workshops that have been run by colleagues from King's College London and elsewhere for the past decade. We shall explore some of the evolving approaches used and strategies taken in the teaching of digital encoding to an audience largely of classicists and historians. Prominent among the assertions of EpiDoc training is that 'encoding' is not alien to, in fact is directly analogous to, what philologists do when creating a formal, structured, arbitrarily expressed edition. We shall share some of the open teaching materials that have been made available, and consider pedagogical lessons learned in the light of EpiDoc practitioners who have progressed from training to running their own projects, as opposed to those who have learned EpiDoc directly from the published Guidelines or via the TEI ( $c f$. Dee, q.v.). We shall also compare the teaching of EpiDoc to the teaching of epigraphy to students, and ask what the pedagogical approaches of both practices (which overlap, since many epigraphic modules now include a digital component, and very rarely teachers of epigraphy are treating EpiDoc as the native format for editing inscriptions) can offer to teachers and learners of both traditional and digital epigraphy.
\end{abstract}

\section{How to cite this book chapter:}

Bodard, G and Stoyanova, S. 2016. Epigraphers and Encoders: Strategies for Teaching and Learning Digital Epigraphy. In: Romanello, M \& Bodard, G (eds.) Digital Classics Outside the Echo-Chamber: Teaching, Knowledge Exchange \& Public Engagement, Pp. 51-68. London: Ubiquity Press. DOI: http://dx.doi.org/10.5334/bat.d. License: CC-BY 4.0. 


\section{Introduction}

This chapter discusses training courses in EpiDoc (TEI markup for epigraphy and papyrology), past and present practices and ideas for future development, and the ways in which it intersects and could be better integrated with the teaching of epigraphy at university level. EpiDoc is one of the most important technical standards for the digital encoding of classics materials, and is the leading format for the structuring and publication of ancient text editions and associated object data. The EpiDoc community makes important contributions to the TEI schema and guidelines through collaborations, conference attendance and membership of technical bodies, and is closely linked to other digital classics communities including Pleiades and Pelagios (for ancient geography), and LAWDI (for ancient linked open data). As an example of the value and utility of digital approaches to classical and ancient historical research, EpiDoc is often taken as exemplary, sometimes to the exclusion of other subdisciplines. We feel it is important therefore to consider what workshops introducing students and scholars to EpiDoc do and indeed should focus on, and whether there is value in closer integration between the teaching of digital epigraphy (for example) and epigraphy tout court.

We shall first present a history of EpiDoc training, from the origins of the practice in project workshops in the early 2000s, to major developments with the Inscriptions of Aphrodisias and Integrating Digital Papyrology projects, before discussing the assumptions and methods embedded in training as it has been carried out over the last ten years. Student feedback will be drawn on to explore some possible models of either advanced or more focussed training programmes, and finally we shall discuss the impact of technical methods and skills on the teaching of epigraphy: itself a technical and methodological discipline sometimes dismissed as ancillary to the study of classics and ancient history (although its ancillarity is that of any research that creates resources on which other research builds). We shall conclude with some observations on the value of digital methods in teaching text editing and research.

\section{History of EpiDoc Training}

The EpiDoc Collaborative produces a set of guidelines, schema and related tools for the encoding of epigraphic and other ancient text editions in TEI XML. The first EpiDoc Guidelines, published in 2000, arose jointly from work on Latin inscriptions by scholars at the University of North Carolina, and from work by the EAGLE Commission of the Association Internationale d'Epigraphie Grecque et Latine. ${ }^{1}$ Since then, many major online editions of inscriptions have been published using EpiDoc, including the Inscriptions 
of Aphrodisias, Vindolanda Tablets Online, US Epigraphy Project, Inscriptions of Roman Tripolitania, Pandektis (Upper Macedonia, Aegean Thrace and Achaia), Roman Inscriptions of Britain and now massive corpora such as the Duke Databank of Documentary Papyri, Datenbank zur jüdischen Grabsteinepigraphik and the EAGLE Europeana Project, make use of EpiDoc in their workflow. ${ }^{2}$

In the meantime there were two major phases in the development of EpiDoc tools and documentation, under the funded Inscriptions of Aphrodisias and Integrating Digital Papyrology projects respectively.

Inscriptions of Aphrodisias was a major AHRC project at King's College London funded for three years from 2004-2007, and preceded by the small pilot project that led the Aphrodisias in Late Antiquity digital publication. In the course of this project, ten international workshops were held, which brought together scholars and practitioners to discuss EpiDoc and the intersections between epigraphic scholarship and archaeology, prosopography, lexicography, numismatics, Byzantine materials and other topics. ${ }^{3}$ These workshops were also the venue for significant practical work on tools such as the EpiDoc Example XSLT and the EpiDoc Guidelines, which reached a state of stability of usefulness for public consumption during this process. ${ }^{4}$

Integrating Digital Papyrology was a Mellon-funded project involving a consortium of institutions, led by Duke University, between 2008-2011. This project produced several major new tools (especially the open source Papyrological Navigator the SoSOL collaborative editing platform ${ }^{5}$ ), and also funded several development and training workshops which further enhanced the EpiDoc Guidelines and training schedule.

Today, an average of two to three times per year, a week-long EpiDoc training workshop is held for trained epigraphists and papyrologists with little to no background in digital skills. ${ }^{6}$ These workshops, run in London and elsewhere, regularly accommodate 20 or so participants (at all levels from undergraduate students to professionals and professors) and are always over-subscribed, sometimes with $50 \%$ or more of the applicants having to be turned away due to lack of space. These week-long events allow time for a basic introduction to XML, detailed discussion of epigraphic features (including text and edition structure) rendered in TEI, plenty of unstructured 'workshop' time and introduction to tools such as the Papyrological Editor and Example Stylesheets for rendering HTML editions.

Although these workshops began in an ad hoc context in London in the early 2000s, they were first funded during the Inscriptions of Aphrodisias project, and underwent a significant evolution-including the addition of training in the use of SoSOL_-during Integrating Digital Papyrology. These workshops are now held in London, Bologna, Rome, Lyon, Sofia and elsewhere fairly regularly, and are often supplemented by shorter, one- or two-day training events attached to discipline conferences or other project meetings. 


\section{What is Taught in EpiDoc Training}

The usual target audience consists of Classical epigraphers and papyrologists with traditional Classics background and little or no digital skills. We assume the knowledge of either Greek or Latin, if not both, and familiarity with the Leiden conventions; a willingness to learn computing methods and an understanding of the need for digital publication is perhaps implied by attendance at the workshops in the first place. In the last few years there has been a rise of interest in EpiDoc from specialists in other epigraphies: Ogham, Campa, Mayan, Arabic, ${ }^{7}$ and so the assumption of familiarity with classical languages should not be restricted to Greek and Latin.

Though the training is chiefly targeted at classical epigraphers, the demographics of the students vary widely. Many of the students are starting work on epigraphic projects which include a digital component, if not a complete digital publication. They tend to have need of immediate and more detailed training. Another distinct group are students and researchers who have more general interest and curiosity about TEI and EpiDoc. Others attend the workshop to acquire basic encoding skills to boost their CVs, which could then help them to find their way into a project. A usually smaller part of the students are technical support specialists and developers, who have also started working on a digital humanities/digital epigraphy project and would like to know what they will be expected to deliver, what technologies and methodologies have been used and are recommended. A fifth group are people from various disciplines with more general interest in TEI and digital humanities.

At the beginning of the training we make clear the limits of the programme: we will show the students how to transform their XML documents into HTML using the generic EpiDoc Example Stylesheets, but will not aim to teach any XSLT coding. It would be unrealistic to include an XSLT tutorial in a week-long workshop targeted at people with little or no technical skills. By the end of the week they understand the principles of XML and can encode more or less easily, but XSLT would require more experience with XML and HTML, which we cannot expect and cannot teach in this time frame.

Another subject we cannot teach at any length is project management. Many of our students are involved or just about to be involved in a project; we will give them the principles of encoding and publishing a corpus in EpiDoc, but we cannot devote much discussion to setting up and managing an entire project, any more than we could cover every possible element of a digital epigraphic edition. While it is by no means obvious to all participants that project management is a key requirement for any digital and especially collaborative work, this issue is a reminder that ongoing support and training is sorely needed, far beyond a few days basic training.

We begin with the assertion that the Leiden conventions are as much a markup language-arbitrary, well-defined, unambiguous_as XML, only designed for a 
human reader. This perhaps counter-intuitive theoretical point is driven home in our introduction to XML, where an example of replacing human-facing with machine-readable markup is shown. The students are then introduced to the EpiDoc Guidelines and a pair of 'Cheatsheets', which take the form of concise tables listing the most frequently needed descriptive features and Leiden sigla, respectively, against their TEI equivalents. ${ }^{8}$ At this stage the students begin to practise usually on their own material. It proves more useful and stimulating for them to do exercises rather than listen to presentations/lectures. This allows them to familiarise themselves with the Oxygen XML Editor, ${ }^{9}$ the XML syntax and the principles of EpiDoc, and to feel more comfortable about encoding, before going into too much detail. After they have done basic encoding on a few texts, they are shown how to perform an XSL transformation to see their texts in human-readable HTML and double-check their encoding-a crucial step in understanding the relationship between digital encoding and multiple outputs.

Until recently the practice was to first introduce the students to the more detailed text markup, and afterwards to the monument description markup, with the presumption that the majority of epigraphers are primarily interested in the text of their inscriptions, and it also logically followed the general introduction and initial exercises. During the 2014 London training workshop the instructors decided to change this sequence and start with an overview of an entire document structure, followed by the monument description part of the publication. The detailed text markup came at the end, after some exercises only on the supporting information. This strategy proved to be clearer and more comprehensible to the students. It shows immediately that the structure of an EpiDoc document is exactly the same as the structure of a traditional epigraphic publication. This gives the students better understanding of the structure of the XML file and makes their work easier and more efficient.

After the students have practiced encoding whole publications with both supporting information and text, they are then introduced to the principles of lemmatizing and indexing in EpiDoc-a crucial point illustrating that the rigorous intellectual effort of indexing in a tradition project is changed in the digital process, but not replaced by an automated process. This part of the training usually comes at the end, because it requires some understanding of certain elements and their application. Also, this structure follows the workflow of an epigraphic project, where the indices, tables of contents, lists of lemmata etc. are produced at the end of the project from the encoded XML files.

In the second half of the training workshop the students are introduced to the Papyrological Editor online editing platform, which is used to enter, edit and translate texts from papyrological collections. ${ }^{10}$ The Papyrological Editor runs on a tags-free editing interface called SoSOL, in which users enter the punctuation and Leiden sigla largely in the form they are used to from traditional editing, with a few innovative sigla (dubbed 'Leiden+') to represent more features in the underlying XML. While SoSOL effectively allows the editing of EpiDoc 
XML via an interface in which tags are invisible, the platform also allows editing directly in XML, and it is worth mentioning that some students claim to prefer working in the XML view of SoSOL, as it allows them more control and flexibility over the encoding, and they find it more transparent than Leiden+.

Other models of EpiDoc training in which we have been involved include: (i) short, one- or two-day workshops attached to conferences, (ii) specific training of students, interns and research assistants and (iii) EpiDoc training re-cast for students as part of digital humanities or other courses. These programmes have been useful in developing methods and materials for the more thorough workshops, and we shall mention some of the significant points here.

(i) Preconference workshops on EpiDoc have been held most recently at the TEI annual conference in Rome in 2013, and the Digital Humanities conference in Lausanne in 2014. These provide a combination of very basic introduction to XML and the EpiDoc mapping of Leiden and conventional editions to TEI, an opportunity to discuss a range of other issues around digital publication of epigraphy and papyrology, such as conversion tools or linked open data, and feedback from the students and users in general on what training, tools or other materials are most wanted from the EpiDoc community. These sessions have been a very useful exercise in giving accelerated introductions to both practical and theoretical concepts, and have been an especially valuable sounding-board for how EpiDoc can be useful outside of the circle of the most active users and developers.

(ii) Student interns and research assistants on EpiDoc-based projects (especially many of those at King's College London) have often been offered an intensive XML and EpiDoc training session over the course of an hour or two. Students are then immediately given the opportunity to put their training into practice, and they familiarise themselves with different aspects of the use of EpiDoc on the job. The fact that they are working under supervision, on already existing projects with access to sample files and documentation, facilitates a rather quick induction and good progress in XML and other skills. The importance of hands-on experience with real materials, and preferably involving texts and records that the student will continue to work on, is highlighted by the success of these events. We have regularly asked students at workshops to bring texts with them so we can try to build on this advantage.

(iii) One of the formats we have taught was a 90-minute class within an MA course on Digital Scholarly Editing and Textual Criticism at the University of Leipzig. The majority of the students were master students in Computer Science, and the humanists were non-epigraphers from different disciplines: Classics, Egyptology, Byzantine Studies, Near-Eastern Studies, Translation and Reception Studies and Linguistics. In this case the class had to be balanced between the very different skills and needs of the students. The computer scientists required as much humanities understanding as the humanists XML 
training. The goal of the class was to demonstrate the dire need of efficient communication between humanists and computer scientists, without which a successful DH project is impossible. After a general introduction to EpiDoc and a live demonstration of encoding an inscription, the instructor drew upon the strengths of each group and specialty represented in the class, which resulted in achieving the desired dialogue and subsequent collaboration between the representatives of these disciplines.

The interdisciplinarity and wide range of interests at these shorter events have added to the richness of the EpiDoc environment, and in particular provided valuable feedback not only on the training itself, but on EpiDoc tools and other materials themselves.

At most training workshops, whether a full week or the half-day introduction, we try to make time for a feedback session where we ask all participants to consider:

1. what they came here expecting to learn, and whether their expectations were satisfied;

2. to what extent EpiDoc is applicable to the material or project they are working on (particularly important in the case of those studying nonclassical epigraphies or other texts);

3. what more they would like to have learned, either in the current workshop or, more speculatively, in a more advanced training event in the future.

These prompts generally lead to in-depth discussion among the students, as well as questions directed at the trainers, and as such helps to bring out a general sense of the attendees' satisfaction with the workshop as a whole. The fruitfulness of these discussions, along with many students' professed need for further feedback on their markup exercises, led the London trainers to set up an EpiDoc Workshop blog at which students can continue these discussions or ask for feedback on XML examples in a more convivial and less-public environment than the Markup discussion list. ${ }^{11}$

Feedback on the current workshop varies from suggestions about the content of training materials, to requests for more exercises, more in-class demonstrations or more structured presentations. These vary from group to group, but are generally very useful in helping to improve the workshops. Comments on both structure and content of the training, on balance between lectures and practice highlight not only the strengths of a current workshop, but also provide coverage of needs, some of which, inevitably, were not met. Responses to the second question have led to some discussion of the value of a workshop directed specifically at epigraphers of non-alphabetic languages (Mayan, Egyptian, Linear A/B, Chinese) and non-linear scripts; such a workshop would be extremely interesting, as the consensus has suggested that while EpiDoc handles such epigraphies reasonably well, some customization is needed 
in the areas of palaeography, linking of glyphs to transcriptions, rendering of languages for which Leiden is not appropriate, and handling of dialects and non-Unicode scripts.

The most interesting question is invariably the third, to which there is regularly a strongly expressed desire for more advanced training in the future. Participants often request further introduction to XSLT, the scripting language used to transform EpiDoc XML to web or print editions, which they encounter, but are not required to understand, in the form of the EpiDoc Example Stylesheets ${ }^{12}$ used to render in HTML, and therefore to some extent sanity test their markup exercises. Other suggestions include: more advanced XML training, such as the encoding of authority lists, bibliographical concordances, prosopographies, and using them to link between texts and editions; more introduction to Linked Open Data for the ancient world, and ways in which EpiDoc editions can link into the LAWD ${ }^{13}$ network; hands-on 'hackfest' events, at which participants take on some task, such as converting a legacy dataset to standards-compliant EpiDoc, building something from an open access EpiDoc corpus, or making and exploiting connections between multiple epigraphic or papyrological datasets; project management information, how to set up, build, run and publish an EpiDoc corpus from the top level: who to hire, who to collaborate with, and what skills to acquire.

\section{Possible Future Models for Teaching EpiDoc}

Participant feedback at the end of EpiDoc workshops is one source of ideas for future models of more advanced or more specialized training events. We also have our own ambitions for the development of EpiDoc, tooling and guidance, and ways in which training workshops fit into the workflows of our own projects, both as testing grounds for methods and as a form of essential public engagement and community benefit from often publicly funded work. (These are the grounds on which both the Aphrodisias and IDP projects, and now the EAGLE Europeana Network, contributed to the EpiDoc community, after all.) We shall discuss now some of the ways in which we would like to see EpiDoc training develop in the future. Some of these might require further (funded) development work before becoming possible, but are worth considering in any case.

At present most projects handle authority lists and controlled vocabularies (e.g. names for types of stone or places of archaeological finding) in idiosyncratic ways, either linking to existing typologies and ontologies or, more often, minting their own. Discussion is ongoing whether to include more guidance on specific vocabularies within the EpiDoc Guidelines, but there is no consistency or consensus on how to achieve it. One step in this direction might be to encourage newcomers to EpiDoc, in the form of attendees at training workshops, to follow the examples of existing practice in generating and 
handling of controlled vocabularies, bibliographies, person- and place-lists, and the indices, concordances, prosopographies and gazetteers that are built upon them. A workshop in this area might focus on a deeper discussion of the principles and implications, recommended encoding and authorities, and give examples from existing projects, both as good practice and as cases where previous usage could be improved.

There has been enthusiasm for a more in-depth introduction to Linked Open Data (LOD) in the context of digital epigraphic training. Especially in the context of the EAGLE Europeana Network, one could well imagine a workshop that introduced both EpiDoc and LOD in tandem; in fact a side effect of this sort of event might be further work on integrating LOD advice and recommendations in the EpiDoc Guidelines themselves. Since one use case of LOD is normalizing to authority lists via RDF, a brief introduction to the topic as part of the above-mentioned vocabularies and authorities workshop is also a possibility, albeit less depth would be possible in that context.

Another technique that would be valuable to address in the process of discussing authority lists, and especially prosopographical and geographical information, is Named Entity Recognition (NER), the process of identifying (perhaps with computer assistance) names of people or places. In a corpus of any size, this is normally a part of the process of linking from instances of names to the authority list that serves to disambiguate and index them. There are some useful techniques involving relatively accessible tools, pioneered for example by the Trismegistos Project, and open source tools such as Recogito, coming out of the Pelagios project and related work. ${ }^{14}$ We have yet to fully integrate any of this activity into the workflow of the epigrapher or papyrologist, however, and further training in this area would doubtless result in better integration with EpiDoc guidance, and quite possibly new project collaborations.

Since the workshops offer basic XML training, a common request for a possible follow-up workshop is further training in XSLT and XPath, tools for the transformation of semantic XML data into online and other publications. After a demonstration of transformations with the EpiDoc example stylesheets, many students have suggested that this would be a more useful next step, whereas they could study more advanced XML and acquire further EpiDoc skills independently.

One key reason we have not implemented this in past training is that XSLT is not an EpiDoc- or even TEI-specific skill. We are unlikely to fit any significant XSLT component into a four-day EpiDoc workshop, and even a dedicated, week-long XSLT course would only scratch the surface, it might be more efficient for those students with a need or desire to study XSLT (which will by no means be all epigraphers), to find a more generic XSLT training programme, perhaps closer to their home institution or even online, or self-study using a book. ${ }^{15}$ The knowledge of XML they acquire is usually enough to give them a good start in an XSLT course. 
One more suggested topic of advanced training was discussion of project management issues and the combination of technical and administrative questions around how to assemble all of the components of a digital corpus into a polished and dynamic online publication. It might be useful to discuss the range of technical and other skills required for a project of this scale, advice on costing the funding bid realistically, identifying user needs and modelling outcomes, and other issues of collaboration. Most of these questions are not specific to an epigraphic or papyrological project, of course, although the answers will be specific to any individual project.

One way to incorporate both programming and project management training into an EpiDoc training context is under development with a project to build an EpiDoc-specific form of the Kiln XML publishing infrastructure, under the title EpiDoc Front-End Services (EFES). ${ }^{16}$ This tool is envisioned as a delivery, search and browse platform that can be set up and customized for an individual EpiDoc XML-based project with only minimal training and technical skill on the part of a project team. The authors of EFES plan to offer advanced, followup training workshops for students already familiar with EpiDoc, but lacking further technical skills, with a view to empowering them to create and manage all stages of their digital publication, from modelling to indexing to publishing online. It remains to be seen how successful this training will be.

\section{Teaching EpiDoc/Teaching Epigraphy}

EpiDoc has mostly been taught to students or scholars who already have a background in epigraphy or papyrology (or at least in classical languages and the rudiments of text editing). There have been students at EpiDoc workshops who come from a technical discipline, or a different branch of the digital humanities, and need to gain some understanding of epigraphy as they go along, but this is less usual. As a result, EpiDoc training has tended to focus on how digitally to express and exploit those intellectual distinctions that we already understand from our grounding in the classics.

Conversely, when epigraphy is taught at university level, usually as a postgraduate module or doctoral methods seminar in ancient history, the vast majority of both lecturers and students lack any knowledge of or even interest in digital humanities methods or principles-even if they have not been actively dissuaded by sceptical mentors. With the possible exception of the use of invaluable online databases for search purposes, epigraphy is often taught today in a way that would not have surprised or dismayed a student of one hundred years ago: texts are read (from autopsy or photographs, or even paper impressions known as 'squeezes'), a preliminary transcription may well be made by hand, editorial conventions, apparatus criticus and commentary are created with a view to printing for reading by scholars knowledgeable in the same conventions, and little thought is given to any afterlife of the publication, since paper publications after all have rather predictable destinations. 
By way of analogy, epigraphy and the texts of inscriptions are sometimes also used as a supplementary topic in the teaching of other subjects; most obviously in an advanced graduate history programme, but also in elementary language teaching. Because of the relatively simple language and formulaic nature of many inscriptions, instructors sometimes use inscriptions (with or without introducing the texts as objects or giving the added challenge of deciphering original letters and scripta continua) to give students the sense of connection to the surviving writings of ancient scribes themselves. ${ }^{17}$ As with the occasional references to technology as an ancillary topic in epigraphy classes, we do not know of any cases in which ancient languages are taught entirely or primarily from epigraphic sources, or in which epigraphic methods are intrinsic to the language course.

Although there have been some experiments in teaching an introduction to epigraphy and digital editing methods in tandem, these are as yet a rarity, and so while they are worth briefly mentioning here, for this section we shall discuss the more common situation which is that digital skills and epigraphic practice are taught in separate circumstances, to distinct audiences, and by lecturers who seldom overlap.

One of the first experiments for integrating digital epigraphy training in a traditional epigraphy class was conducted by Monica Berti in 2010 and 2013 at Tufts University. ${ }^{18}$ At the end of her Latin epigraphy module, four classes were devoted to introducing the principles and best practices of digital epigraphy. Students were given a brief training in EpiDoc and practised with texts from the Epigraphic Database Roma. ${ }^{19}$ Another project she was involved with was the 2011 epigraphy and archaeology programme 'The Stones of Ancient Latium, ${ }^{20}$ held in Italy, which provided students with EpiDoc training alongside the teaching of epigraphy in museums and in the field.

As discussed above, the Digital Philology masters module at Leipzig has recently begun bringing together students with backgrounds in the humanities and informatics with a view to teaching traditional and digital encoding of ancient texts as a single skill-set, fostering the levels of collaboration and interdisciplinarity necessary for work in this area, and bringing the technical and disciplinary values of both communities to bear on a single problem. ${ }^{21}$ In a separate exercise, colleagues in Classics and the university library at Duke University in 2015 began teaching an epigraphy seminar to graduate students in Classics there, in which the principles of digital editing, EpiDoc encoding and the SoSOL interface are presented not as a new, special or unusual way to encode epigraphic editions, but simply as an integral part of the epigrapher's toolkit, much as paper and ink, or a word processor and Greek font are presented in most traditional epigraphy classes. ${ }^{22}$

Professors of ancient history at Bologna University, where EpiDoc workshops have been taught regularly for several years, regularly involve students of epigraphy in encoding EpiDoc editions both of project texts and their own coursework. ${ }^{23}$ Similarly, the 2015 Roman epigraphy graduate seminar at Brown University for the first time did not include separate training in and 
preparation of Leiden editions, but students were taught EpiDoc editing from scratch, using the homegrown US Epigraphy Project ${ }^{24}$ XML template with the basic metadata filled in according to the USEP supporting information structure. In addition to the EpiDoc training provided in class, there were also several lab open sessions, as well as more general discussion of EpiDoc and digital epigraphy issues during the seminar. ${ }^{25}$ Personal sources inform us that Oxford is planning a similar introduction to EpiDoc as part of Greek and Latin epigraphy training in the near future, but there is no public record of this programme as yet.

In practice, however, EpiDoc training and the teaching of epigraphy are usually distinct operations, and for the remainder of this chapter we shall describe the world in which there is seldom significant overlap between the two. The parallels in the way they are taught are nevertheless striking, albeit unsurprising when we consider the technical, arguably ancillary, nature of the epigraphic discipline itself.

As we lay out in Table 1 below, the introductory sessions in a typical epigraphic seminar follow a very similar structure to the content of an EpiDoc workshop. The epigraphy lecturer assumes that students come to their class with advanced knowledge of Greek and Latin, but is prepared to teach the technicalities and disciplinary habits of epigraphic practice from the very beginning. Students are provided with reference materials in the form of standard epigraphic handbooks, and usually customized summaries of important conventions such as the Leiden sigla and other explanations of the form and appearance of an edition. The core of the teaching of epigraphy is then via practice; students read as many texts as possible in the time available, produce their own transcriptions and commentaries, exercising the skills acquired under the supervision of the tutor.

Typically in an epigraphy course as taught in a classics or ancient history department, there may be one class devoted to introducing the students to digital resources. They are shown various online databases of texts and images, search and reference tools, concordances. They are likely to learn how to use these resources from a user's point of view, with little or no attention paid to the underlying infrastructures, limiting the understanding and insight into

\begin{tabular}{|l|l|}
\hline \multicolumn{1}{|c|}{ Teaching EpiDoc } & \multicolumn{1}{c|}{ Teaching epigraphy } \\
\hline Assume epigraphic/classical knowledge & Assume Greek and Latin \\
\hline Introduce technology & Introduce epigraphic practice \\
\hline $\begin{array}{l}\text { Give reference materials (Guidelines) } \\
\text { and customized summary of reference } \\
\text { (Cheatsheets) }\end{array}$ & $\begin{array}{l}\text { Give reference materials (handbooks) } \\
\text { and customized summary of reference } \\
\text { (Leiden conventions) }\end{array}$ \\
\hline Give lots of exercises and practice & Give lots of exercises and practice \\
\hline
\end{tabular}

Table 1: Comparison of Teaching EpiDoc with Teaching Epigraphy. 
the process of creating a digital resource (which insight, it should not need explaining, would be very valuable to students and indeed scholars who need to know how to assess the unique value and shortcomings of the tools of their trade).

Often a guest lecturer from outside the classics department may be invited to give such a class at the end of term, further highlighting the impression that this is somehow 'special', outside the curriculum, less academic and worthy of attention from the serious classicist. On the other hand the digital humanities specialist may take the opportunity to use such a class to show the students the process of digital creation and research, in the way that a traditional epigrapher might not, via for example an exercise in deciding which features of an epigraphic transcription and edition are worth encoding digitally and exploiting through transformation, indexing or search.

In a similar way, some epigraphy courses have included one or two classes dedicated to learning EpiDoc encoding, as in the classes at Tufts, described above. The principles and benefits of an electronic publication are explained, as well as a realistic summary of the additional training needed. The focus of such a class is not so much an intensive EpiDoc training, but rather demonstrating that structured markup is nothing more than structured thinking about data. The structure of an XML document reflects the structure of an epigraphic edition. Following the strict hierarchy of XML forces one to better organise one's thoughts, approach towards, and work on an epigraphic document. We have found that it is highly beneficial to be able to process and produce information in a well structured and clearer way, even if the students do not show interest in further DH training.

The introduction to digital editing and electronic publishing also stresses the importance of scientific attribution, credit and responsibility. In a humanities publication more often than not some aspects of the decision making process are left fuzzy and not very visible. Since an electronic publication implies making a text machine actionable, all decisions (or uncertainties about a decision) have to be explicitly expressed, visible, recording the evidence which lead to them and pointing to the person responsible for each decision. In this way, proper attribution and credit can be given, as well as a clear statement of responsibility and degree of certainty.

These principles which are widely applied to digital publications, lead to a more 'scientific' approach to research and publication. Clear, explicit statements and visible attribution have long been features more characteristic of publications in the natural sciences, than in the humanities. In digital humanities, however, they are the norm. Thus, for the traditionally trained epigrapher (classicist, humanist) an EpiDoc or a more general DH training leaves the sense of a distinct change of methodology. This change, however, is usually perceived as an improvement, the 'scientific' methodology adding more detail and nuances to the publication, though sometimes it can leave an uncomfortable feeling of not being allowed any fuzziness. 


\section{Conclusions and Recommendations}

The parallels between the methods and outcomes in the teaching of EpiDoc, as detailed in this chapter, and the teaching of traditional documentary disciplines such as epigraphy, lead to some interesting observations. Both are highly technical sets of skills, but involve deeply interpretive materials, require a balance of precision and flexibility, and engage with a community of practice and reference materials. As we have observed, teaching the two skill sets in parallel would bring tangible benefits to students. And although the uni-disciplinary nature of most university degree modules seems to limit the practicality of such a unified approach at the moment.

There are a number of benefits that come with EpiDoc training, aside from simply being able to do EpiDoc. Even if students do not go on to work on an EpiDoc-based project, they have acquired a set of valuable transferable skills beyond the realm of digital epigraphy: structured way of thinking about and producing data, management of complex sets of information and collaborative project work. One such crucial skill in the realm of research, is approaching one's subject of study (in our case epigraphy) from outside one's comfort zone, being able to look, question and explore it from different perspectives based on different bases, needs and project objectives. For instance, digital encoding of data and semantics often involves the disambiguation of concepts that prose descriptions express in a fuzzy way-this need to disambiguate is not always comfortable: scholars complain of 'spurious exactitude ${ }^{26}$ when asked to express 'early fourth century' as a figure, for example. The attention this forces us to pay to our own writing can only be valuable, however.

Some of the approaches to EpiDoc training, and in particular the use of SoSOL for transcribing and editing papyrological editions in the Duke Databank or annotating photographs and translations in Perseids and the EAGLE Europeana Project, walk the frontier between traditional practice-based teaching and crowdsourcing. Trevor Owens has argued that the leveraging of social information and enthusiasm often known as crowdsourcing is at its best when it benefits the contributors both by imparting research skills and feeding a thirst for discovery. ${ }^{27}$ We would go further and suggest that the educational and public engagement benefits of crowdsourcing activities are more significant and important than the content creation or enrichment achieved by the process.

Students of digital epigraphy learn to 'look under the hood' of the digital tools they use and even more importantly, to understand the reasoning behind the construction and design and the functionality, of these tools. This practice in turn encourages them to think about possible methods to apply in their own research, while assessing the suitability and relevance of the digital humanities methodologies to their own field.

Digital epigraphy also provides valuable lessons for the teaching and studying of digital humanities. Practice-based learning, including working with tools in a classroom lab, lies at the base of much digital humanities study; similarly 
in epigraphy, students create epigraphic editions as part of the learning process. Introducing and practicing the principles and best practices of digital humanities reasoning and publishing gives the students a number of transferable skills applicable above and beyond the field of epigraphy, Classics and the humanities in general. As such, the field of digital humanities is often seen as a bridging discipline or a bridge between disciplines, considering its inherent need for interdisciplinarity.

Our observations in this chapter are offered by way of highlighting the apparent differences between the teaching and learning of two skill sets (digital editing and publication versus autopsy-based philology) to argue for bringing the disciplines together. As well as hoping that there are lessons for both groups of educators in the other's area, we believe that just as the philologist learns by applying digital methods to her traditional practice, so students from both areas will gain a deeper understanding of their discipline by studying the traditional and digital methodologies side-by-side, or rather, as a neatly dovetailed unit. We have used the example of epigraphy and digital epigraphy to make this case here, but we believe the conclusions stand across a much larger array of digital classics and even philology as a whole.

\section{Acknowledgements}

The authors would like to thank the editors, the publishers' peer reviewers, and also Pietro Liuzzo, Franco Luciani and Jonathan Prag for constructive feedback on the contents of this chapter.

\section{Notes}

1 See 'About EpiDoc' at <http://epidoc.sf.net/>; fuller history at Cayless \& Roueché 2009 ('1.3 EpiDoc') and Bodard 2010, pp. 101-4; On the EAGLE commission, see Panciera 1999.

${ }^{2}$ EpiDoc projects listed and described at <https://wiki.digitalclassicist.org/ Category:EpiDoc $>$.

${ }^{3}$ Inscriptions of Aphrodisias: Calendar, available <http://www.insaph.kcl. ac.uk/project/calendar/index.html>.

${ }^{4}$ Bodard 2008, $\$ 4$.

${ }^{5}$ Esp. Baumann 2013; cf. Sosin 2010. Papyrological Navigator, available $<$ http://papyri.info/>; SoSOL ('The Son of Suda-Online'), available <http:// github.com/papyri/sosol>.

6 'EpiDoc Summer School', available <http://wiki.digitalclassicist.org/ EpiDoc_Summer_School>.

${ }^{7}$ Ogham in 3D <ogham.celt.dias.ie/>; Corpus of the Inscriptions of Campā $<$ http://isaw.nyu.edu/publications/inscriptions/campa/>; Textdatenbank und Wörterbuch des Klassischen Maya <http://www.iae.uni-bonn.de/ 
forschung/forschungsprojekte/laufende-projekte/idiom-dictionary-ofclassic-mayan>; Digital Archive for the Study of pre-Islamic Arabian Inscriptions $<$ http://www.dasiproject.eu/ $>$.

${ }^{8}$ Guidelines, see Elliott, Bodard et al. 2007-; Cheatsheets, see Bodard 2006-2015 and Bodard \& Stoyanova 2014.

${ }^{9}$ Oxygen XML Editor, <http://oxygenxml.com/>, while a commercial tool, is considered to be so rich in features, including XSLT transformation, and available under a reasonable education license, that it is currently without competitor among the free offerings available. Students often use a free 30-day demo version, and of course free XML tools are available for projects for whom even the modest $\$ 99$ cost is a barrier.

${ }^{10}$ Papyrological Editor, available: <http://papyri.info/editor>; on PE and SoSOL, see Baumann 2013.

${ }^{11}$ EpiDoc Workshop Blog. Available: <http://epidocworkshop.blogspot. $\mathrm{com} />$.

${ }^{12}$ EpiDoc Example Stylesheets, see Elliott, Au et al.

${ }^{13}$ On the Linked Ancient World Data (LAWD) initiative, see $<$ http://lawd. info/> and <http://wiki.digitalclassicist.org/Category:LAWDI > .

${ }^{14}$ On Trismegistos NER, see Depauw \& Van Beek 2009; Recogito, see Simon, Barker, et al. 2013-2015.

${ }^{15}$ E.g. Tennison 2005, or W3Schools online XSLT tutorial at $<\mathrm{http} / /$ w3schools.com/xsl>.

${ }^{16} \mathrm{Kiln}$, see Vieira, Norrish, et al. 2011-2015; EFES under development at $<$ https://github.com/EpiDoc/EFES>.

${ }^{17}$ See e.g. LaFleur 2010; similar ideas proposed by Rubenstein 2003; Carpenter 2006; cf. Parisinou \& Shipley 2004.

${ }^{18}$ Syllabus, Berti 2010.

${ }^{19}$ Epigraphic Database Roma: <http://www.edr-edr.it/>.

${ }^{20}$ Berti \& Harrington 2011.

${ }^{21}$ Syllabus, Berti 2014.

22 Sosin, Baumann \& Cayless 2015.

${ }^{23}$ Bencivenni \& Agrimoni 2014.

${ }^{24}$ US Epigraphy Project: <http://usepigraphy.brown.edu/>.

${ }^{25}$ Bodel \& Mylonas 2015.

26 Tarte 2011.

${ }^{27}$ Owens 2012.

\section{References}

Baumann, R. (2013). The Son of Suda On-Line. In Dunn \& Mahony (Eds.) The Digital Classicist 2013 (pp. 91-106). Bulletin of the Institute of Classical Studies supplement 122, London: Institute of Classical Studies, University of London. 
Bencivenni, A. \& Agrimonti, S. (2014). The IGCyr Project: Encoding Codes, Translating Rules, Communicating Stones in Ptolemaic Cyrene and in Contemporary Bologna. In Orlandi et al. (Eds.) Information Technologies for Epigraphy and Cultural Heritage (pp. 351-368). Collana Convegni 26, Roma: Sapienza Università Editrice. Retrieved from http://www.eaglenetwork.eu/wp-content/uploads/2015/01/Paris-Conference-Proceedings. pdf

Berti, M. (2010). Latin Epigraphy, Syllabus, Fall 2010. Tufts University. Retrieved from http://www.monicaberti.com/wp-content/uploads/2015/09/Latin_ Epigraphy_Syllabus_2010.pdf

Berti, M. (2014). Module: Digital Scholarly Editing and Textual Criticism 1 (DH.DSE-1). University of Leipzig. Retrieved from http://www.dh.unileipzig.de/wo/courses/winter-semester-2014/module-digital-scholarlyediting-and-textual-criticism-winter-semester-20142015/

Berti, M. \& Harrington, J.M. (2011). The Stones of Ancient Latium. Inscriptions and Archaeological Remains, and the Geographic Contexts of Latium Vetus. Retrieved from http://sites.tufts.edu/latiumvetus/

Bodard, G. (2006-2015). EpiDoc/Leiden Cheatsheet. Retrieved from https:// sourceforge.net/p/epidoc/code/HEAD/tree/trunk/guidelines/msword/ cheatsheet.doc

Bodard, G. (2008). The Inscriptions of Aphrodisias as electronic publication: A user's perspective and a proposed paradigm. Digital Medievalist 4. Retrieved from http://digitalmedievalist.org/journal/4/bodard/

Bodard, G. (2010). EpiDoc: Epigraphic Documents in XML for Publication and Interchange. In F. Feraudi-Gruénais (Ed.), Latin On Stone: epigraphic research and electronic archives (pp. 1-118). Plymouth: Lexington Books.

Bodard, G. \& Stoyanova, S. (2014). EpiDoc Structure Cheatsheet. Retrieved from https://sourceforge.net/p/epidoc/code/HEAD/tree/ trunk/guidelines/ msword/structure-cheatsheet.docx

Bodel, J. \& Mylonas, E. (2015). Epigraphy Seminar: Syllabus. Brown University. Retrieved from<http://cds.library.brown.edu/projects/usepigraphy/Latin Epigraphy2014/RomEpig2014-Syllabus.pdf>

Carpenter, B. (2006) MAGISTER DISCIPVLIS H F: Using Funerary Epigraphy with Intermediate Students of Latin. CPL Online 3.1. Retrieved from http:// www.camws.org/cpl/cplonline/files/Carpentercplonline.pdf

Cayless, H., Roueché, C., Bodard, G. \& Elliott, T. (2009) Epigraphy in 2017. Digital Humanities Quarterly 3.1. Retrieved from http://digitalhumanities. org/dhq/vol/3/1/000030/000030.html

Depauw, M. \& Van Beek, B. (2009). People in Greek Documentary Papyri. First Results of a Research Project. Journal of Juristic Papyrology 39: 31-47.

Elliott, T., Au, Z., Bodard, G., Cayless, H., Lanz, C., Lawrence, K.F., Vanderbilt, S., Viglianti, R. et al. (2008). EpiDoc Example Stylesheets (version 8). Retrieved from https://sourceforge.net/p/epidoc/wiki/Stylesheets/ 
Elliott, T., Bodard, G., Mylonas, E., Stoyanova, S., Tupman, C., Vanderbilt, S. et al. (2007). EpiDoc Guidelines: Ancient documents in TEI XML (Version 8). Retrieved from http://www.stoa.org/epidoc/gl/latest/

Fernando-Luis, Á., García-Barriocanal, E. \& Joaquín-L. G. (2010). Sharing Epigraphic Information as Linked Data. In Sanchez-Alonso \& Athanasiadis (Eds.), Metadata and semantic research (pp. 222-234) Heidelberg: Springer.

Flanders, J. \& Roueché, C. (2005). Introduction for Epigraphers. EpiDoc Guidelines. Retrieved from http://www.stoa.org/epidoc/gl/latest/intro-eps.html

LaFleur, R. A. (2010). Scribblers, Sculptors, and Scribes: A Companion to Wheelock's Latin and Other Introductory Textbooks. New York: HarperCollins.

Owens, T. (2012). The Crowd and the Library. Series of 4 blog posts. Retrieved from http://www.trevorowens.org/2012/05/the-crowd-and-the-library/

Panciera, S. (1999). Nouvelles de l'AIEGL 1999. Epigraphica 61: 311-313. Retrieved from http://www.eagle-eagle.it/Italiano/Documenti/Document2_ it.html

Parisinou, E. \& Shipley, G. (2004). Hellenizein: A Flexible Structure for Teaching Greek to Archaeologists and Ancient Historians. Milton Keynes: Higher Education Academy.

Rubinstein, L. (2003). The use of inscriptions in language teaching. Paper presented at the Classical Association Annual Conference, Warwick. Programme available at http://www.classicalassociation.org/pastconferences/ Warwick\%202003.pdf

Simon, R., Barker, E. et al. (2013-2015), Recogito. Available at https://github. $\mathrm{com} /$ pelagios/recogito

Sosin, J. D. (2010). Digital Papyrology. Congress of the International Association of Papyrologists, 19 August 2010, Geneva. Available at http://www. stoa.org/archives/1263

Sosin, J. S., Baumann, R. F. \& Cayless, H. A. (2015). GRK582s Epigraphy: syllabus s15. Duke University. Available at http://people.duke.edu/ jds15/grk582s/syllabus-s2015.html

Tarte, S. (2011). Digitizing the act of papyrological interpretation: negotiating spurious exactitude and genuine uncertainty. Literary and Linguistic Computing 26(3): 349-358. Available at http://llc.oxfordjournals.org/ content $/ 26 / 3 / 349$

Tennison, J. (2005). Beginning XSLT 2.0. Berkeley: APress.

Vieira, J.-M., Norrish, J., Giacometti, A. et al. (2011-2015). Kiln. Available at https://github.com/kcl-ddh/kiln/ 